\title{
Physicochemical and Immunochemical Studies on the Reaction of Bovine Serum Albumin with $p, p^{\prime}$-Difluoro- $m, m^{\prime}$-dinitrodiphenylsulfone
}

\author{
SAROJ S. TAWDE, ${ }^{1}$ J. SRI RAM ${ }^{2}$ AND M. RAJA IYENGAR ${ }^{3}$ \\ From the Department of Pathology, The University of Michigan, Ann Arbor, Michigan; and the Department \\ of Biochemistry and Nutrition, School of Public Health, The University of Pittsburgh, \\ Pittsburgh, Pennsylvania
}

Received August 27, 1962

\begin{abstract}
Bovine serum albumin (BSA) was reacted with the bifunctional reagent $p, p^{\prime}$ difluoro- $m, m^{\prime}$-dinitrodiphenylsulfone (FNPS) under varying conditions. While intramolecular cross linkages involving the lysine and tyrosine residues were the major modifications, formation of intermolecular linkages (dimerization), favored by high protein concentrations, was observed under all conditions studied. The modified derivatives exhibited decreased precipitin reactions with the antiserum prepared against the native protein indicating that the protein was denatured to some extent during the modification. FNPS appears useful as a general reagent for conjugation of two proteins.
\end{abstract}

\section{INTRODUCTION}

Reaction of proteins with bifunctional reagents can give rise to three types of modification: (a) intramolecular cross linkages, $(b)$ intermolecular cross linkages resulting in dimers or higher polymers, and (c) simultaneous intra- and intermolecular cross linkages. Wold (1) reported that the bifunctional reagent $p, p^{\prime}$-difluoro- $m, m^{\prime}$ dinitrodiphenylsulfone (FNPS) reacted with bovine serum albumin (BSA) forming intramolecular NPS bridges to give a derivative with almost unchanged hydrodynamic and antigenic properties. The new cross linkages apparently stabilized the over-all structure of BSA from denaturation by heat, alkali, urea, oxidation, and reduction, but the more subtle features responsible for the integrity

1 Visiting investigator from Indian Institute of Science, Bangalore, India. Present address: Walter Reed Institute for Research, Washington, D. C.

2 Communications concerning this article may be addressed to The University of Michigan.

${ }^{3}$ Present address: Max Planck Institute for Medical Research, Heidelberg, W. Germany.

These studies were supported by U. S. Public Health Service Grant E-4401. of the antigenic sites were lost after heat treatment (2). An extension of these studies revealed that in addition to intramolecular linkages, intermolecular linkages were also formed on reaction of BSA with FNPS, suggesting the possible usefulness of FNPS as a reagent for conjugation of two proteins.

\section{EXPERIMENTAL}

Crystalline BSA was obtaincd from Armour and Co. Rabbit $\gamma$-globulin (RGG) and egg albumin (EA) were products of Pentex, Inc. The various amino acids used were purchased from Nutritional Biochemicals Corporation. FNPS was prepared as described by Zahn and Zuber (3).

\section{Reaction of FNPS with Proteins}

This was carried out essentially as described by Wold (1), by adding the desired volume of an acetone solution of FNPS $(15.6 \mathrm{mg} . / \mathrm{ml}$.) to the protein dissolved in $1 \%$ sodium carbonate. The reaction mixture was stirred until clear, extensively dialyzed against distilled water, and lyophilized. All the products were yellow and water soluble. A variety of derivatives of BSA were prepared by changing the protein to FNPS molar ratio, concentration of the protein and temperature. In the following, each derivative was designated by a letter denoting the temperature of its preparation (room temperature or cold), with the 
molar ratio of FNPS to BSA and protein concentration as subscripts. A derivative of EA corresponding to $C_{10,1 \%}$ was also prepared. In one experiment a mixture of $\mathrm{BSA}$ and $\mathrm{RGG}$ in the proportion of 3:1 (by weight) was reacted with FNPS under conditions corresponding to $C_{10,1 \%}$.

\section{NPS-Lysine}

$N_{\mathbf{E}}, N^{\prime}{ }_{\mathbf{E}}-\left(m, m^{\prime}\right.$-Dinitrodiphenylsulfone- $\left.p, p^{\prime}\right)$ his-I-lysine, was prepared as described by Wold (1).

\section{Acetylated BSA}

Two derivatives were prepared as described previously (4), but with smaller amounts of acetic anhydride, to give about 40 and $75 \%$ acetylation.

\section{Characterization of NPS Derivatives OF BSA}

\section{Estimation of NPS Groups}

No method for the direct estimation of the number of NPS groups introduced in the protein was described in the earlier work (1). In the present studies, the yellow color of absorption maximum of $420 \mathrm{~m} \mu$ given by the product of reaction of FNPS with amino acids and proteins was utilized to devise an assay system for the NPS groups of the derivatives. FNPS $(0.1-1.0 \mu M)$ dissolved in $0.2 \mathrm{ml}$. acetone was reacted with 3 $\mathrm{ml}$. of $2 \%$ lysine in $1 \%$ sodium carbonate at room temperature. After $1 \mathrm{hr}$. of reaction, the mixture which was initially turbid became clear. (Excess of amino acid insured complete reaction of FNPS without any concomitant hydrolysis.) The solution was diluted to $25 \mathrm{ml}$. and read against a blank containing the amino acid and acetone. The calibration curve relating moles of FNPS to the absorbancy at $420 \mathrm{~m} \mu$ is given in Fig. 1. Similar calibration experiments were also performed with glycine (which gave comparable values with lysine), eysteinc, histidine, scrinc, and alanine (which gave about 1.4 times the color relative to lysine), and tyrosine (which gave only a third of the color given by equimolar amounts of lysine). The absorbancy at $420 \mathrm{~m} \mu$ of suitable dilutions of the various NPS proteins was determined against an appropriate solution of the unmodified proteins as blanks, and the moles of NPS groups per mole of the protein were determined from the calibration curve. The molecular weight of BSA was assumed to be 69,000 .

The following inherent limitations of this method are recognized: (a) Reaction products of FNPS with amino groups alone are yellow. As FNPS reacts with tyrosyl groups also, these derivatives may go undetected by this method

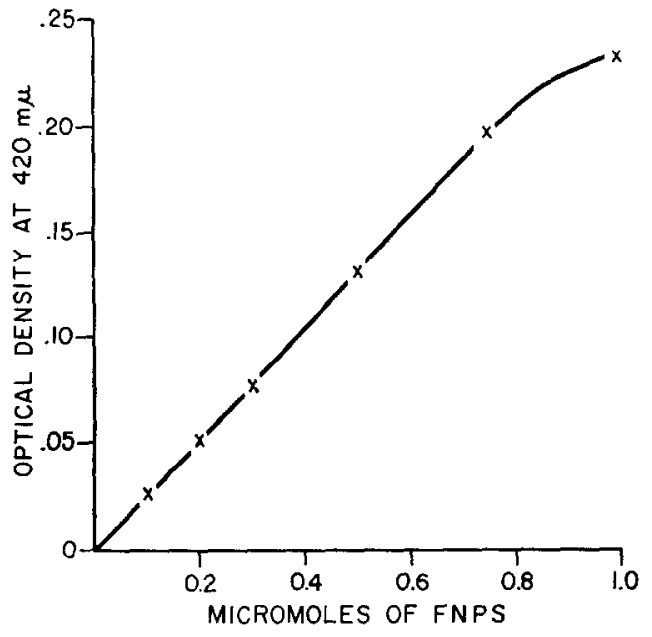

FIg. 1. Calibration curve for the estimation of NPS groups. Various amounts of FNPS in $0.2 \mathrm{ml}$. acetone were reacted with $3 \mathrm{ml}$. of $2 \%$ lysine in $1 \%$ $\mathrm{Na}_{2} \mathrm{CO}_{3}$. O.D.420 of the reanted products was estimated.

unless at least one of the two functional groups reacts with an amino group. (b) This procedure utilizes the color value of an amino acid for calibration purposes. It is questionable whether the molar extinction coefficient of NPS-lysine remains the same when the amino acid is part of a polypeptide chain.

\section{Amino Acid Analyses}

The protein samples were analyzed for the constituent amino acids by the method of Spackman et al. (5), using a Beckman automatic recording amino acid analyzer. Fach determination was performed in triplicate.

\section{Sedimentation Studies}

The lyophilized protein samples were dissolved in sodium phosphate buffer $(0.05 M, \mathrm{pH} 7.0)$, dialyzed against $500 \mathrm{vol}$. of the same buffer, stirred at $4^{\circ} \mathrm{C}$., and used for subsequent studies.

\section{Approach to Equilibrium}

Archibald's method of approach to equilibrium was employed (6). A $1.0 \%(\mathrm{w} / \mathrm{v})$ solution was centrifuged at $20 \pm 0.2^{\circ} \mathrm{C}$. in a spinco model $\mathrm{E}$ ultracentrifuge equipped with RTIC unit. The protein solution $(0.6 \mathrm{ml}$.) was layered over $0.1 \mathrm{ml}$. of Dow-Corning No. 555 silicone fluid. Centrifugation was carried out for $64 \mathrm{~min}$., and pictures were taken at 16 -min. intervals at a bar angle of $80^{\circ}$ on Kodak metallographic plates. The plates were evaluated (7) after tracing the patterns at 
$8 \times$ enlargement. Synthetic boundary runs were carried out under the same conditions in a cuptype cell (8).

\section{Sedimental Velocity}

Sedimentation velocity experiments were carried out at a speed of 59,780 r.p.m. The sedimentation coefficients were compared using a two-dimensional microcomparator ${ }^{4}$ and reported as Svedberg units converted to standard conditions in water at $20^{\circ} \mathrm{C}$. The per cent of protein polymerized was estimated by measuring the areas under the schlieren patterns during the velocity sedimentation runs. The total area under the pattern was measured in an earlier picture before the faster sedimenting peaks had separated. The area under the main slower peak was measured in a later picture after it had separated from the faster sedimenting aggregates. The difference between the two, after applying correction for radial dilution, is reported as per cent of total area. Due to the enhancement of the area under the slow peak caused by the JohnstonOgston effect (9), the values for the polymers are probably minimal.

\section{Diffusion}

Diffusion coefficients were estimated by the spreading of protein-solvent boundary formed in a cup-type synthetic boundary ultracentrifuge cell. The dialyzate, $0.2 \mathrm{ml}$., was layered over $0.35 \mathrm{ml}$. of protein solution, and the degree of spreading was followed at a speed of 10,589 r.p.m. The apparent diffusion coefficients were calculated from the schlieren pattern by the heightarea method. Zero-time correction was applied by extrapolating the apparent diffusion coefficients to infinite time, and was then corrected for standard conditions $\left(20^{\circ} \mathrm{C}\right.$. in water $)$. No correction was applied for the dependence of sedimentation coefficient on concentration (10) since at the low centrifugal field employed its effect was considered to be small.

\section{Estimation of Total $N$, Amino Nitrogen and Tyrosyl Groups}

Nitrogen content of the protein solution was estimated by the Markham modification of the micro-Kjeldahl procedure (11).

The residual amino groups of the derivatives were estimated by the colorimetric ninhydrin procedure (12). As the plots relating the amount of protein to the color do not pass through the origin, the method described by Schick and Singer

${ }^{4}$ David W. Mann, Inc., Lincoln, Mass.
(13) for the calculation of per cent loss in amino groups was employed.

Tyrosyl groups were estimated as described by Herriot (14).

\section{Paper Euectrophoretic Studies}

Electrophoretic patterns of the derivatives were studied on cellulose acetate paper in barbital buffer, $\mathrm{pH}$ 8.6. After the run the dried paper strips were stuined wilh $0.2 \%$ poncesu in $3 \%$ trichloroacetic acid and washed with dilute acetic acid. In some experiments, the separated spots were eluted in $0.1 \mathrm{~N} \mathrm{NaOH}$ and estimated colorimetrically at $560 \mathrm{~m} \mu$.

\section{Proteolysis Studies}

Rates of hydrolysis of BSA and the various derivatives by trypsin, chymotrypsin, and pepsin were determined as described previously (15).

\section{IMMUNOCHEMICAL STUDIHS}

Rabbit antisera against BSA and NPS-BSA $\left(R_{10,1 \%}\right)$ were obtained using alum-precipitated antigens in a single course of immunization. Calibration of antisera and calculation of cross reactions were described previously (16).

\section{Inhibition Experiments with NPS-Lysine}

To three 1-ml. aliquots of anti-NPS-BSA serum were added $0.07,0.35$, and $0.7 \mathrm{mg}$, respectively, of NPS-lysine in normal saline and incubated for $0.5 \mathrm{hr}$. at $35^{\circ} \mathrm{C}$. One milliliter of antigen corresponding to the equivalence point was then added, and after 6-7 days incubation in the cold, the specific precipitates were estimated. Controls contained the antiserum, the antigen, and $1 \mathrm{ml}$. of normal saline.

In another experiment, six $1-\mathrm{ml}$. aliquots of the antiserum (in duplicate) were incubated with $1 \mathrm{mil}$. of saline containing $0.7 \mathrm{mg}$. NPS-lysine prior to the addition of $1 \mathrm{ml}$. of the antigen. Each day for 6 days, the test solutions and the controls (which contained no NPS-lysine) were centrifuged, and the specific precipitates were estimated. At the highest concentration of NPSlysine used, the molar ratio of "inhibitor" to antibody was estimated to be at least 250 .

\section{Heat Denaturation of Antigen}

Approximately $1 \%$ solutions of the proteins in $0.05 M$ phosphate buffer, $\mathrm{pH} 6.9$, were incubated for $25 \mathrm{~min}$. in a boiling water bath. The cooled solutions were used in subsequent studies without further treatment. 


\section{Gel Diffusion Studies}

The technique of Allison and Humphrey (17) was employed with slight modifications. A large Petri dish contained $1.5 \%$ agar. In the center a narrow rectangular slit was made to contain antiserum. On either side of this antibody a series of cylindrical holes were made equidistant from the canal as well as from each other; in these were placed gelatin solutions of varying concentrations which were allowed to set around small wells designed to contain the antigen solutions (Fig. 5 represents this arrangement). The antigen diffusing out of the gelatin cylinder would thus come in contact with the antibody under the conditions of the Ouchterlony technique (18) and give a precipitin band. Gelatin cylinders of concentrations of $10,15,20,25$, and $30 \%$ protein, were employed in these studies. After introducing the antigens and the antiserum into the appropriate wells, the Petri dishes were maintained at 2-4 ${ }^{\circ} \mathrm{C}$. until precipitin bands appeared (4-6 days).

\section{RESULTS AND DISCUSSION}

In studies with amino acids, FNPS reacted with $\alpha$-amino and $\epsilon$-amino groups giving yellow NPS derivatives. Glycine required only one-half the molar equivalent of the reagent for complete reaction, while lysine required equimolar amount, indicating that both of the functional groups of the reagent fully participate in the reaction (1). The low color reaction obtained with tyrosine may have been due to a preferential reaction of FNPS with the phenolic hydroxyl over the $\alpha$-amino group. When cysteine was reacted with an excess of FNPS, the product still gave a positive nitroprusside reaction, suggesting that the sulfhydryl group was free.

\section{Reaction of FNPS WITH BSA}

The extent of modification of the various amino acid residues of BSA was evaluated by total amino acid analysis of BSA and the NPS derivatives. In Table I the data for BSA obtained under our experimental conditions are compared with the values of Stein and Moore (19). On reaction with FNPS, only the lysyl and tyrosyl residues of BSA decreased. Cysteine content was not determined. The extent of modifications of tyrosyl and amino groups was also estimated by the colorimetric procedures. But these methods, although reproducible,
TABLE I

Amino Acid Composition of BSA

\begin{tabular}{lcc} 
& \multicolumn{2}{c}{ Moles/69,000 g. } \\
\cline { 2 - 3 } & & \\
& Present studies Stein and Moore \\
\hline Asparagine & 56.2 & 56.5 \\
Threonine & 32.7 & 33.7 \\
Serine & 26.5 & 27.7 \\
Glutamic acid & 79.8 & 77.4 \\
Proline & 31.6 & 28.5 \\
Glycine & 17.2 & 16.7 \\
Alanine & 45.5 & 48.4 \\
Valine & 30.4 & 34.5 \\
Methionine & 3.9 & 4.3 \\
Isoleucine & 12.1 & 13.7 \\
Leucine & 63.9 & 64.5 \\
Tyrosine & 19.8 & 19.3 \\
Phenylalanine & 25.8 & 26.2 \\
Lysine & 60.2 & 60.4 \\
Histidine & 17.3 & 17.8 \\
Arginine & 23.0 & 23.4 \\
\hline
\end{tabular}

proved unsuitable for determining the number of residues modified.

In Table II are presented the sedimentation and diffusion data on the various NPS derivatives with the extent of chemical alteration determined from complete amino acid analyses. Control BSA, treated in the same manner as the modified derivatives except for the addition of FNPS, was indistinguishable from native BSA. Different preparations of the same NPS derivative showed variations which could have arisen if some FNPS precipitated from acetone on addition to the protein solution, making the reaction partly heterogeneous. It is to be noted that all of the preparations contained a faster sedimenting component, probably a dimer. Hughes (20) reported a value of 6.5 for the sedimentation constant of the mer cury dimer of mercaptalbumin. Moore and Ward (21) obtained dimers of BSA with sedimentation constants ranging between 6 and 6.5 ; on reacting $\mathrm{BSA}$ with the bifunctional sulfhydryl reagent, $N, N^{\prime}-(1,3-$ phenylene)bismaleimide. Up to $40 \%$ of the protein appeared as dimer. In the present studies, the proportion of the dimer increased when the reaction was carried out at higher protein concentrations. The differences in the sedimentation rates of the mono- 
TABLE II

Characterization of NPS Derivatives of BSA

\begin{tabular}{|c|c|c|c|c|c|c|c|c|c|}
\hline \multirow{3}{*}{ Derivatives } & \multicolumn{4}{|c|}{ Reaction conditions for preparation } & \multirow{3}{*}{$\begin{array}{l}\text { No. of } \\
\text { NPS } \\
\text { groups } \\
\text { found/ } \\
69,000 \mathrm{~g} .\end{array}$} & \multirow{2}{*}{\multicolumn{2}{|c|}{$\begin{array}{l}\text { Amino acid } \\
\text { residues } \\
\text { reacted } \\
69,000 \mathrm{~g} .\end{array}$}} & \multirow{3}{*}{$\begin{array}{l}\text { Sedimentation } \\
\text { constant }(\mathbf{s})^{b}\end{array}$} & \multirow{3}{*}{$\begin{array}{l}\text { Difusion } \\
\text { constant }\end{array}$} \\
\hline & \multirow{2}{*}{$\begin{array}{c}\text { Moles } \\
\text { of } \\
\text { FNPS } \\
\text { taken } \\
\text { per mole } \\
\text { of BSA }\end{array}$} & \multirow{2}{*}{$\begin{array}{l}\text { Concen- } \\
\text { tration } \\
\text { of BSA }\end{array}$} & \multirow{2}{*}{ Time } & \multirow{2}{*}{$\begin{array}{c}\text { Temper- } \\
\text { ature }\end{array}$} & & & & & \\
\hline & & & & & & Lysine & Tyrosine & & \\
\hline & & $\%$ & $h r$. & ${ }^{\circ} \mathrm{C}$. & & & & Svedberg Units & 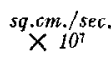 \\
\hline Control (BSA) & & & & & 0 . & 0 . & 0 . & 3.8 & 4.46 \\
\hline$R_{10,1 \%}(1)$ & 10 & 1 & 1 & $20-25$ & 10.5 & 9.7 & 8.0 & $4.2(73 \% ; 6.0(27 \%)$ & 5.86 \\
\hline (2) & & & & & 10.1 & 11.8 & 7.4 & $3.9(78 \%) ; 6.3(22 \%)$ & 5.32 \\
\hline$C_{10,1 \%}$ & 10 & 1 & 1 & $2-4$ & 9.8 & 13.5 & 5.4 & $3.9(75 \%) ; 5.1(25 \%)$ & 6.00 \\
\hline $\mathrm{C}_{20,1 \%}$ & 20 & 1 & 24 & $2-4$ & 16.6 & 20.9 & 9.2 & $4.4(66 \%) ; 5.3(31 \%)$ & 1.90 \\
\hline$C_{20,2 \%}$ & 20 & 2 & 24 & $2-4$ & 14.0 & 21.0 & 8.8 & $4.3(64 \%) ; 6.0(36 \%)$ & \\
\hline$C_{10,20} \%$ & 10 & 20 & 24 & $2-4$ & 4.7 & 3.0 & 3.0 & $3.7(45 \%) ; 5.6(55 \%)$ & \\
\hline (2) & & & & & 7.2 & 4.8 & 2.4 & $4.1(44 \%) ; 6.1(56 \%)$ & \\
\hline
\end{tabular}

${ }^{a}$ Calculated from the differences in the amino acid composition of BSA and the respective NPS derivatives.

${ }^{b}$ The figures in parentheses represent the percentage of component.

mers, as well as the dimers, in the various preparations indicate varying degrees of conformational changes under different reaction conditions. The diffusion coefficients are to be taken only as approximate since it is difficult to evaluate the true diffusion coefficients of polydisperse systems by the technique employed.

All of the derivatives appeared homogeneous on paper electrophoresis, and the change in mobility relative to BSA was in conformity with the increased negative charge resulting from the loss of amino groups. Formation of intermolecular cross linkages mediated by FNPS was also confirmed on paper electrophoresis. For this, BSA was reacted with $\mathrm{RGG}$ under conditions of the preparation $C_{10,1 \%}$ in the ratio of $3: 1$ by weight. The reaction product exhibited, on paper electrophoresis, a third component, moving with a mobility intermediate to that of $\mathrm{BSA}$ and RGG and constituting $8-10 \%$ of the total protein.

\section{Proteolysis Studies}

In Fig. $2(A-C)$, the rates of hydrolysis of BSA are compared with those of various NPS derivatives utilizing trypsin, chymotrypsin, and pepsin. Reaction of BSA with FNPS resulted in an apparent reduction in the rates of hydrolysis by the three enzymes as measured by the liberation of TCAsoluble peptide fragments. Loss of $\epsilon$-amino groups of lysine, which contribute bonds susceptible to trypsin (22), and tyrosine residues $(22,23)$, which provide points of attack at the carboxyl end to chymotrypsin and at the amino end to pepsin, should result in reduced susceptibility to these enzymes. The derivative $C_{20}, 2 \%$ in which only about one-third of lysine residues and one half of tyrosines were modified, twothirds of the lysine residues, and all the guanidyl groups of arginine (22) should still provide susceptible bonds to trypsin. But this derivative, in the assay system employed here, appeared totally inert not only to trypsin, but to chymotrypsin and pepsin as well. One explanation for this is that the intramolecular bridges might render large areas of the protein unavailable to the cnzymes. Another possible explanation is that the formation of intramolecular linkages might prevent the release of TCA-soluble fragments even though peptide bonds have been cleaved by these enzymes. On heating the derivative $R_{10,1 \%}$ its susceptibility to trypsin and chymotrypsin increased slightly. no such increase was observed with pepsin; Thus some subtle changes appear to take 

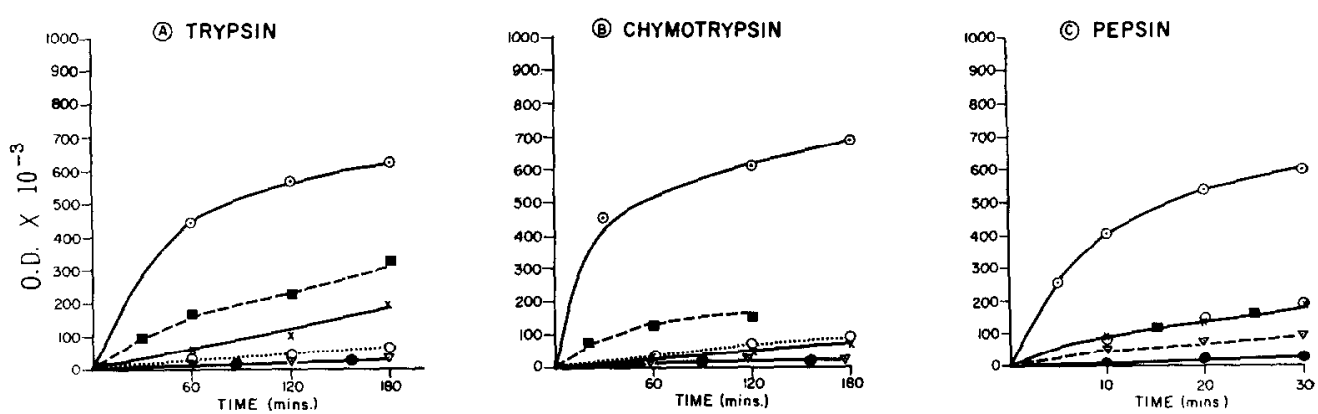

FIG. 2. Rates of proteolysis of BSA and NPS derivatives. A. Trypsin reaction mixtures: $105 \mathrm{mg}$. protein in $15 \mathrm{ml}$. water $+17 \mathrm{ml}$. of $0.1 M$ borate buffer $\mathrm{pH} 7.85+1 \mathrm{ml}$. enzyme $(200 \mathrm{mg} . \%)$. Total volume $33 \mathrm{ml}$. Digestion at $25^{\circ} \mathrm{C}$. At specified time intervals $4 \mathrm{ml}$. of reaction mixture was removed and $3 \mathrm{ml}$. of $10 \%$ TCA was added to stop the reaction. O.D.280 of the filtrates was estimated. $B$. Chymotrypsin: Reaction mixtures as described for trypsin. C. Pepsin reaction mixtures: $50 \mathrm{mg}$. protein in $27 \mathrm{ml}$. of $0.1 \mathrm{~N} \mathrm{HCl}+1 \mathrm{ml}$. enzyme $(42$ mg.\%). Other details as described above. $\odot, \mathrm{BSA} ; \mathrm{X}-\mathrm{X}, R_{10,1 \%} ; \boldsymbol{D}, R_{10,1 \%}$ (heated); $\mathrm{O}$, $C_{10,1 \%} ; \nabla, C_{20,1 \%} ;$ and $\bullet, C_{20,2 \%}$.

place on heating NPS derivatives. In previous studies (15), heating BSA resulted in a 15-fold increased susceptibility to trypsin and chymotrypsin, while the rate of hydrolysis by pepsin became lower.

\section{Immunochemical Studies}

The effect of modification of BSA with INPS on the precipitin reaction with antiBSA is shown in Fig. 3. Aggregated or denatured proteins generally are shown to exhibit a pattern of decreased sensitivity to antigen excess in the precipitation reaction (24). In addition to such a decreased sensitivity to antigen excess, all the NPS derivatives exhibited decreased cross reactions with anti-BSA $(60-80 \%)$. As the ultracentrifugal studies have indicated the presence of varying amounts of dimers in all the NPS derivatives, these precipitin curves represent the composite of the behavior of the monomers and dimers of each preparation. Since previous studies have shown that neither the amino (16) nor the tyrosyl $(25,26)$ groups of BSA were important for the reaction with its antibodies, the decreased cross reactions of the derivatives with anti-BSA are attributable to "denaturation" occurring during the modification reaction, denaturation being defined to include all nondegradative conformational changes of the protein. Moreover, differences in the sedimentation constants of the monomers as well as dimers

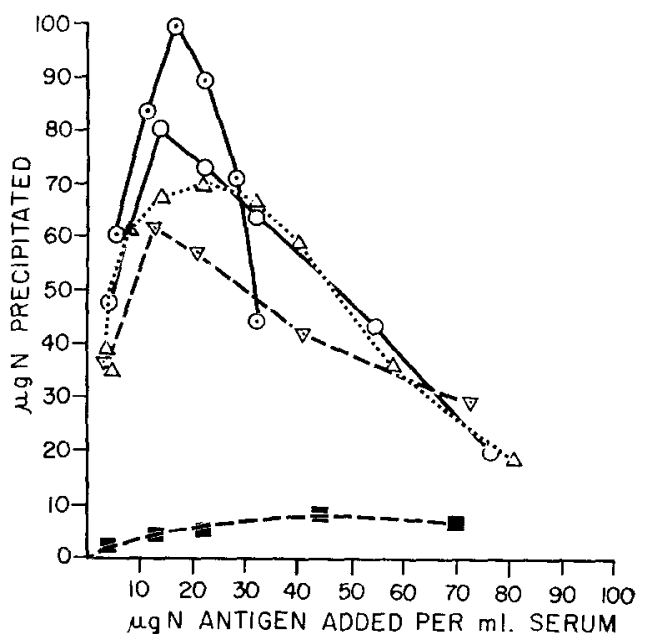

FIG. 3. Precipitin reactions of BSA and NPS derivatives with anti-BSA (Dil. $1 \rightarrow 5$ ). $\odot$, BSA; $\triangle, R_{10,1 \%}(1$ and 2$) ; O, C_{10,1 \%} ; \nabla, C_{20,1 \%}$; and $\square$, $R_{10,1 \%}$ (heated).

(Table II) prepared under different reaction conditions also suggest conformational changes. On heating $R_{10.1 \%}$ its reactivity with anti-BSA was almost completely lost, in agreement with the finding of Wold (1).

Precipitin studies with the antibodies obtained against NPS derivative $R_{10,1 \%}$ are presented in Fig. 4. BSA exhibited a poor cross reaction $(25 \%)$ with the antiserum produced against the modified derivative. This would suggest that significant struc- 
tural alterations have taken place in BSA during the modification and that some of the modified configurations are the major determinants in the antibody producton (27). Cross reactions of other NPS derivatives with this antiserum did not correlate with the number of NPS groups. In fact, a second preparation of $R_{10,1 \%}$ gave a lower cross reaction than $C_{20,1 \%}$ or $C_{20}, 2 \%$, which were prepared under entirely different conditions. Some structural features accompanying the modification reaction, rather than the introduced NPS groups, thus appear to be the

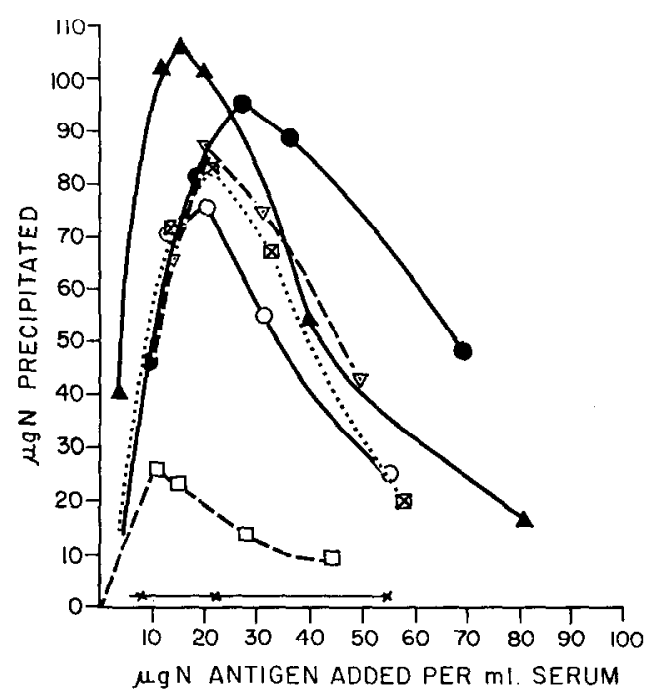

FIG. 4. Precipitin reactions of the BSA and NPS derivatives with anti-NPS-BSA $\left(R_{10,1 \%}\right)$ (Dil. $1 \rightarrow 2.5)$. $\Delta, R_{10,1 \%}(1) ; \otimes, R_{10.1 \%}(2) ; 0$, $C_{10.1 \%} ; \nabla, C_{2 n .1 \%} ; \bullet, C_{20.2 \%} ;[], \mathrm{BSA}$; and $\times-\mathrm{X}$, $R_{10.1 \%}$ (heated). common antigenic features shared by the various NPS derivatives. This was confirmed by the absence of any cross reaction between NPS-EA and anti NPS-BSA and by the inhibition experiments with NPS-lysine. NPS-lysine at a molar excess as high as $\mathbf{2 5 0}$ did not inhibit the reaction of $R_{10}, 1 \%$ with its homologous antiserum. As this apparent lack of inhibition could arise if NPS-lysine did combine with the antibodies but was gradually displaced by the NPS-BSA in the 6-7 days of incubation employed, the extent of inhibition was also studied as a function of period of incubation (1-6 days). None was observed at any stage of the precipitin reaction.

\section{Gel Diffusion Studies}

Attempts were made to compare the molecular weights of BSA and NPS derivatives by the technique of Allison and Humphrey (17). BSA diffused through a gelatin concentration of $25 \%$, but not $30 \%$, in agreement with these authors. This would correspond to a molecular weight of about 70,000. All of the NPS derivatives, surprisingly, gave a single precipitin band and exhibited similar diffusion patterns (Fig. 5); none of them diffused at a concentration higher than $15 \%$. This would correspond to the presence of a single component in all of the preparations, of a molecular weight of about 150,000 , if the molecular weight were the only factor determining diffusion through the gelatin. As this conclusion is at variance with ultracentrifugal studies which showed the presence of one

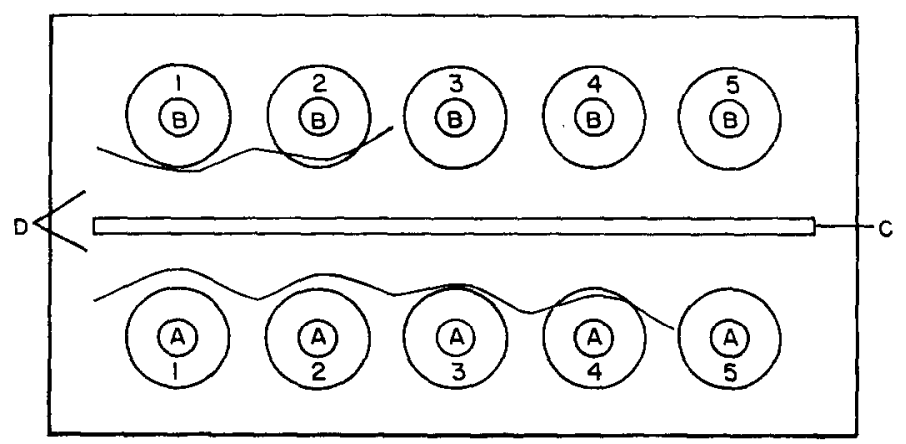

FIG. 5. Gel diffusion studies. 1-5. Gelatin cylinders, concentrations 10, 15, 20, 25, and $30 \%$, respectively. $A$. Well containing BSA. $B$. Well containing NPS-BSA. $C$. Trough containing anti-BSA. D. 15\% agar medium. 
half or more of the monomeric component in all of the preparations, the possibility that the decreased net positive charge of the protein (due to the reaction of amino groups with FNPS) might have caused the observed diffusion pattern was considered. Acetylation reaction decreased the net positive charge of a protein without significant change in molecular weight $(4,28)$. In gel diffusion, acetylated BSA was found to behave exactly like the NPS derivatives, failing to diffuse through a gelatin concentration of $20 \%$. It would thus appear that changes in net charge of the protein could lcad to erroneous conclusions, if one relied solely on diffusion characteristics in gelatin, for determination of molecular weight of proteins.

\section{COMMENTS}

These studies revealed that the reaction of BSA with FNPS is accompanied by some configurational changes in the protein. Furthermore, although the reaction is predominantly intramolecular, some intermolecular linking (dimerization) takes place under all conditions studied. By the choice of appropriate conditions, it appears possible to direct the reaction predominantly toward one or the other type of cross linking.

Intramolecular linkages are of interest since they may stabilize the native structure of the protein. With BSA, although stabilization from gross changes by conditions which usually cause denaturation was observed (1), subtle configurational changes, detectable by sensitive immunochemical and biochemical techniques, were not prevented.

Formation of intermolecular covalent linkages between two protein molecules is of practical interest. In addition to bismalcimide (21) referred to earlier, bis-diazotized benzidine is a possible reagent as this was used to prepare aggregated globulin (29). Diisocyanates have been used to prepare antibody-ferritin conjugates, but a twostep reaction eliminating the direct contact of the reagent and antibody had to be employed as the antibody was otherwise inactivated (30). Furthermore, the chemistry of this reaction appears poorly understood as the amount of the reagent bound to the protein was unaccountably high (13). Employing FNPS, conjugation of antibody to ferritin was accomplished under conditions causing little inactivation of antibody (31). Conjugates of BSA with RGG and EA were also prepared by means of FNPS, ${ }^{5}$ and it appears possible to employ FNPS as a general reagent for conjugation of proteins.

\section{REFERENCES}

1. Woud, F., J. Biol. Chem. 236, 106 (1961).

2. Wold, F., Biochem. et Biophys. Acta 54, 504 (1961).

3. ZAHN, H., AND ZUBER, H., Ber. 86, 172 (1953).

4. Ehrenpreis, S., Mavrer, P. H., and Ram, J. SRI, Arch. Biochem. Biophys. 67, 178 (1957).

5. Spackman, D. B., Stein, W. H., and Moore, S., Anal. Chem. 30, 411 (1958).

6. Archibald, W. J., J. Phys. \& Colloid. Chem. 51, 1204 (1957)

7. Klainer, S. M., and Kegeles, G., J. Phys. Chem. 59, 952 (1955).

8. Pickels, E. G., Methods in Med. Research 5, 107 (1952).

9. Johnston, J. P., And Ogston, A. G., Trans. Faraday Soc. 42, 789 (1946).

10. Baldwin, R. L., Biochem. J. 65, 490 (1957).

11. Markham, R., Biochem. J. 36. 790 (1942).

12. Harding, V. J., and McLman, R. M., J. Biol. Chem. 24, 503 (1916)

13. Schick, A. F., ANd Singer, S. J., J. Biol. Chem. 236, 2477 (1961).

14. Herriot, R. M., J. Gen. Physiol. 19, 283 (1935-36).

15. Ram, J. Sri, and Mavrer, P. H., Arch. Biochem. Biophys. 70, 185 (1957).

16. Maurer, P. H., Ram, J. Sri, and Ehrmarreis, S., Arch. Biochem. Biophys. 67, 196 (1957).

17. Allison, A. C., And Humphrey, J. H., Nature 183, 1590 (1959); Immunol. 3, 95 (1960).

18. Ouchterlony, O., Arkiv Kemi Mineral. Geol. B26, 1 (1949); 1, 43 (1950).

19. Stein, W. H., and Moore, S., J. Biol. Chem. 178, 79 (1949).

20. Hughes, W. L., J. Am. Chem. Soc. 69, 1836 (1947).

21. Moore, J. E., and Ward, W. H., J. Am. Chem. Soc. 78, 2414 (1956).

22. Bergmann, M., and Fruton, J., Advances in Enzymol. 1, 63 (1941); BergmanN, M., Advances in Enzymol. 2, 49 (1942).

23. Neurath, H., and Schwert, G. W., Chem. Revs. 66, 69 (1950); Green, N. M., AND

s. Sri Ram, in preparation. 
Nevrath, H., in "The Proteins" (Neurath and Bailey, eds.), Vol. II, Pt. B., Chap. 25. Academic Press, New York, 1954.

24. Kabat, E. A., and Mayer, M. M., "Experimental Immunochemistry," 2nd ed., p. 63, 450. C. C Thomas, Springfield, Ill., 1961; Heidelberger, M., "Lectures in Immunochemistry," p. 145, Academic Press, New York, 1956.

25. Ram, J. Sri, and Maurer, P. H., Arch. Biochem. Biophys. 74, 119 (1958).

26. Ram, J. Sri, Bier, M., And Maurer, P. H., Advances in Enzymol. 24, 105 (1962).

27. Maurer, P. H., and RaM, J. SRI, in "Sero- logical and Biochemical Comparisons of Proteins" (Cole, ed.). Rutgers Univ. Press, New Brunswick, N. J., 1958.

28. Ram, J. Sri, Terminiello, L., Bier, M., and Nord, F. F., Arch. Biochem. Biophys. 52, 464 (1954).

29. Ismizaka, T., and Ishizaka, K., Proc. Soc. Expll. Biol. Med. 101, 845 (1959); Ishizaka, K., AND Ishrzaka, T., J. Immunol. 85, 163 (1960).

30. Singer, S. J., And Schick, A. F, J. Biophys. Biochem. Cytol. 9, 519 (1961).

31. Tawde, S. S., and Ram, J. SRi, Arch. Biochem. Biophys. 97, 429 (1962). 